\title{
Homo informaticus and Information society - some critical comments
}

\author{
Peter Karl Fleissner, \\ Full professor with tenure at Vienna University of Technology, retired, private consultant / \\ Address: Jakschgasse 12/3, A-1140 Vienna, Austria \\ E-Mail: fleissner@arrakis.es \\ Tel.: +43-676-930-8906; Fax: +43-1-504-1190
}

\begin{abstract}
In the background of the on-going multiplecrisis the author describes a few technoeconomic and cultural trends of society are assessed and evaluated with respect to their contribution to contemporary information society and homo informaticus. The effects of the trends on human behaviour and their humane potential are described. To see the changes more clearly it seems useful to take a long-term perspective on these issues to compare the presence with the past phases of capitalism. On the technological level the paper deals with the emergence of the information processing machinery (IPM). Its fast diffusion is not only driven by economic aspects, but is also triggered by long-term ideas related to religious concepts. Together with changes in the means of production the behaviour of human beings is influenced and transformed.
\end{abstract}

\section{Mechanical machinery}

In his opus magnum "Das Kapital" Karl Marx has analysed the special features of a new type of society, based on privatized means of production and the exploitation of free labour. One century later Karl Polanyi gave a comprehensive and detailed picture of the concrete processes accompanying the "Great Transformation" in England in the first half of the $19^{\text {th }}$ century from market economy to "market society", particularly by mobilizing the workers. From here capitalist society spread all over the globe. Both, Marx and Polanyi ${ }^{1}$ were convinced that the primary cause of market society had to be located on the social level, and that it is based on the specific relations of production, but nevertheless technology cannot be neglected as one of the essential drivers of the creation of wealth. Mechanization was the technical backbone of Industrial Revolution. Embedded in a capitalist society on the one hand it increased productivity of labour, on the other hand it created unemployment and misery. Is there anything we can learn from those insights for our contemporary situation? Is it possible to identify some features of modern technology and its effects on the labour force which remind us to the past?

\footnotetext{
1 "Social not technical invention was the intellectual mainspring of the Industrial Revolution" (Polanyi: p. 119).
} 
Marx characterized the mechanical machinery (MM) in the following way: "All fully developed machinery consists of three essentially different parts, the motor mechanism, the transmitting mechanism, and finally the tool or working machine." (Marx 1867). Over the decades some parts of the mechanical machinery were fundamentally changed. New principles of energy transformation were applied. The motor mechanism, firstly a steam engine, was replaced by electro-mechanical drivers, by the combustion engine and by the gas turbine. Nevertheless the basic structure of mechanical machinery survived (see fig. 1 lower half). What were the effects to the workers? One of the most important effects of technology on human beings was the relocation of specific human activities to technical artefacts. The machine tool deprived (and also relieved) the worker of the individual handling of the object of work and of the controlling of the tool. At the same moment the worker as the source of mechanical energy was replaced by the motor mechanism. To quote Marx: "No longer does the worker insert a modified natural thing [Naturgegenstand] as middle link between the object [Objekt] and himself; rather, he inserts the process of nature, transformed into an industrial process, as a means between himself and inorganic nature, mastering it. He steps to the side of the production process instead of being its chief actor" (Marx 1857/58). By this "side step" during Industrial Revolution labour productivity grew by a multiple of up to 200 (as in the case of Spinning Jenny), and human beings were partly relieved from heavy mechanical activities, but technical innovation per se did not change the relations of production. Instead, exploitation and alienation increased. Technology was only the medium of this increase, while the origin of exploitation and alienation remained deeply rooted in the capitalist social fabric.

\section{Information Processing Machinery}

A hundred years later the replacement of human labour by mechanical devices was more or less completed. Technical innovation was now centred on other, nonmechanical aspects of human work. Actually, around the middle of the $20^{\text {th }}$ century a new type of machinery emerged, the "Information Processing Machine" (see fig. 1, upper half). From this innovation information society took its point of departure. It allowed already transforming human perception, human decision-making (even under changing conditions) and human intervention into functions of the new technology. Human senses can now be replaced sensors (microphones, videocameras, thermometers, keyboards and touch-pads etc.); decision making can be done by electronic devices (first electro-mechanical relays, followed by radio valves, transistors and microprocessors, which are still shrinking); and actors like (mechanic and electronic) switches, relays, printers, video-screens etc. allow to communicate the decisions of the machinery to the outside world. 


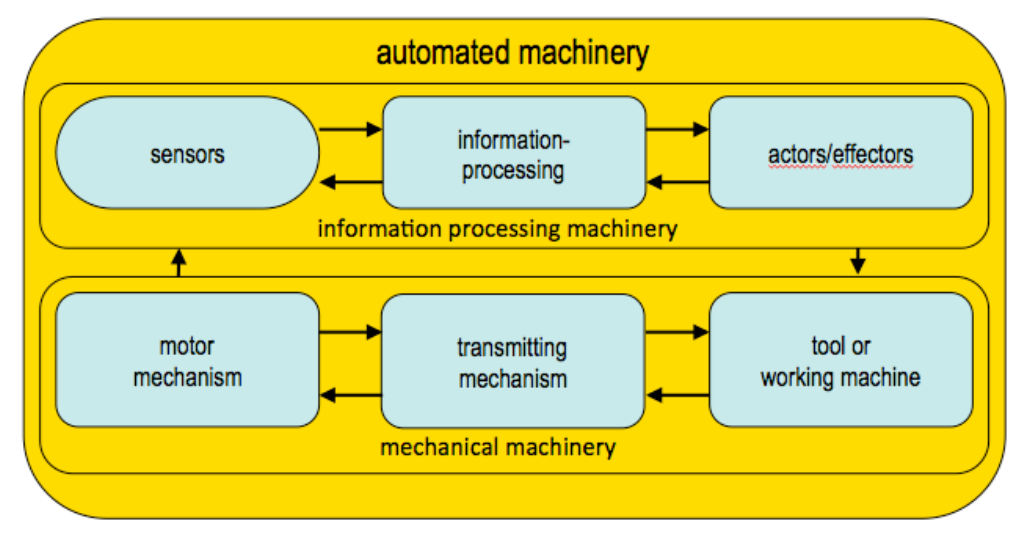

Today the Information Processing Machine is applied in three different contexts:

- Firstly, it can easily stand on its own (as mainframe computer, as personal or laptop computer or as microprocessor in smart phones);

- Secondly, in combination with the mechanical machinery the Information Processing Machine is essential for most of the automation processes. It monitors and controls the mechanical machine according to computer programs (fig. 1). By that it eliminates live labour and boosts the productivity of the remaining workers towards new highs. Human beings are no longer needed for those activities of the production process, which were their monopoly before;

- Thirdly, the Information Processing Machine can be used within an electronic network. Examples are the Internet and mobile phones.

One of the immediate effects of the Information Processing Machine used in networks was a tremendous reduction of transaction costs (Fleissner 1995). In a narrow (economic) sense a transaction cost is a cost incurred in making an economic exchange and the cost of participating in a market (Commons 1931); in an extended meaning of the term transaction costs are also applicable also to non-market activities, including all kinds of efforts of information, communication, administration, coordination and collaboration. By means of the Information Processing Machine these activities can now be done at reduced cost or nearly free of charge, and all that with growing speed and higher quality. This change in transaction costs didn't only trigger structural changes in the formal economy, but also in the private households. In the market sector new players emerged, like Microsoft or later Google, other enterprises disappeared, and in sectors outside the market many NGOs and other institutions of civil society were created from scratch, while the ones already existing could organize their activities more cheaply and effectively.

While replacement of human activities by the now digital machinery was one way the transformation took place the ubiquity of the Information Processing Machine 
changed also the behaviour of the users and their perception of the world. We will come back to this aspect later.

\section{From small communities to society - and back?}

As this was not only true for private enterprises and public administrations, but also for private individuals (e.g. e-mail services), it created high expectations towards the fulfilling of basic dreams of humanity. And, in fact, many observers of the contemporary social fabric emphasize the increased fragmentation, lack of cohesion and social coldness of Western societies. This can be seen partially as a result of the contradictory and conflicting transitions from mainly community based, small scale, informal relations between people towards large scale, abstract, rational and calculated relations to modern society (Tönnies; Weber; Fleissner 2002). On the level of communication, communities are characterized by local and direct face-to-face communication, while in modern societies there is a definite need for communication and interaction between distant individuals. It would be interesting to know to what degree the fast diffusion of digital communication devices and social networks can be seen as a the reaction to the capitalist society with its anonymity and market rationality. The new forms of being a friend could maybe seen as a compensation of traditional forms of human relations.

\section{A short excursion to Heaven}

Another hypothesis to explain the fascination of the Internet, social networks and mobile communication could be linked to religious concepts - although in a secular disguise: some properties of God like the divine features of Omnipresence and Omniscience get new actuality. I know that with this hypothesis I am walking on shaky grounds, but in an interdisciplinary conference like this one I dare to bring it to the fore. In my opinion the properties, which are ascribed to God since ages, reflect the desires and wishes of the people. The content of religious beliefs represent some archetypes, which are deeply rooted in our emotional structure. Technology responds to these desires in a certain way. As a hypothesis I would state that Internet technologies and mobile communication fulfil to a certain degree the desires of human beings to be omniscient and omnipresent.

With the emergence of the "information society" an additional piece of the prophecy of the serpent to Adam and Eve will be fulfilled: "You will be as God" (Genesis 3:5). ${ }^{2}$

\section{Information goods and information commodities}

Let us go down to earth again. Within half a century the term "information" became nearly as important as the terms "matter" and "energy", but it is still less well defined.

\footnotetext{
${ }^{2}$ Unfortunately, up to date not all of God's properties fell down to earth yet: still mercy, love and wisdom are missing widely.
} 
In the context of Shannon's Theory of Information it is seen as a pattern of bits on an exchangeable carrier, which can be transported through "channels" where the patterns may be disturbed, and in some cases also recovered. This objectified perspective on information is sufficient for the definition of an "information good" as a collection of bits of a certain structure, while linguists and philosophers insist on a more relation oriented definition of information. It is input as well as output of the Information Processing Machine. The information good can represent texts, music, pictures, videos or any kind of software. The information good is an excellent example to illustrate the effect of the contemporary social structure. Although the information good is not a rival one (it is not destroyed by consuming it) and it can be easily copied and transported via digital networks, the capitalist system could not resist to limit artificially its use and its global availability by the process of commodification. This is is performed in a dual way, by technical and by legal means. Copy protection mechanisms add uniqueness to a special copy (like a physical good like an apple is unique) and intellectual property rights transform the copying process into a crime. The social system uses Technology and Law to transform the freely available information good into a costly information commodity. The former abundance is replaced by scarcity. The immediate result is the emergence of information markets. In combination with all the electronic devices to retrieve and store information in digital form a fully-fledged industry was born from scratch. In addition to that digital communication offered a new world wide market for information services by providing more or less smart mobile phones and other supporting electronic devices. The appropriation of profits became possible in a new, still growing field.

Figure 2. illustrates the process of commodification and commercialisation. There is an inherent difference between information goods and information services. Many cultural activities can be reified or codified into digital patterns on a carrier. They represent information goods. While goods can be transferred, stored and accumulated, digital services (e.g. telephone or TV service) disappear at the moment of production. In Marxian terminology: Although services could have a price, and are able to attract surplus value or allow for making profits, they do not add to the surplus product. This makes them unable to play any direct role in physical accumulation or capital investment. 
Figure 2: The transformation of information goods into commodities

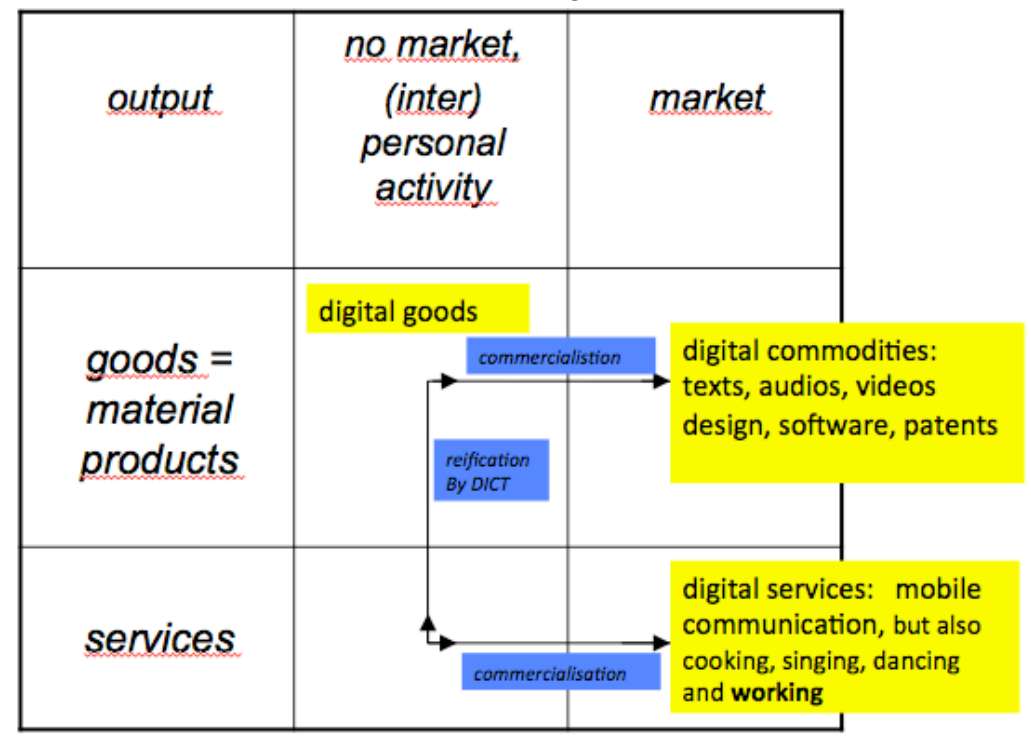

\section{Social effects}

On the social level we can see that the Information Processing Machinery in its networked form influence the behaviour of people. The exchange of information by means of high-tech multi-functional devices, which are able to record voices, to take pictures, to store them and to pass them over to their friends has become one of the most important activities of children and even grown-ups. As we are made aware by Edward Snowden, all these data is transferred to large-scale institutions of surveillance. It seems to be real fun, but the author cannot be helped to think that all the digital gimmicks are a kind of a distraction from more serious issues. The culture of exchanging selfies is booming. This corresponds very well with the methodological individualism we can find in mainstream micro-economics where the individual entrepreneur is in the centre of the game. In this way there seems to be a strong link between homo economicus and homo informaticus. The mass media are echoing and supporting this tendency: Casting shows are strengthening self-control of the individual to be adapted according to the demands of the media and the needs of enterprises. Advertising and marketing campaigns once more focus on the individual, not on the community. Advertising slogans like "Geiz ist geil" ("tight is right"), "Ich habe nichts zu verschenken" ("I don't give anything away for nothing") or "einer hat es, einer wills" ("one owns it, the other wants it" ... and takes it) underline selfish behaviour. Hedonism flourishes. Also the behaviour during leisure time has been changed. Personal contacts are permanently interrupted by emails or other messages on the smart phone. Permanently being online and available for others ruins any ability for contemplation and thoughtful concentration. Virtual realities offer seductive places for entertainment. There is a shift away from longer term planning of meetings towards more spontaneous forms. But also mobbing has increased by using Facebook and other social media. Although there were high expectations in the early stages of the new media with respect to increased democracy, awaiting a 
power shift in favour of the lower strata of hierarchies, we had to learn that only a small minority is really using the digital machinery for political purposes.

\section{Conclusion}

The author has some reason to argue that principles, structures and processes, where many individuals are involved practically, continuously or frequently will shape individual values and individual behaviour of the people. We observe a spread of egotism and egocentricity. Community-based forms of production, distribution and living are disrupted. Solidarity and mutual help have come under pressure. What is the reason of this trend? One of the main roots of spreading selfishness seems to lie in the basic structure of our economy, the legal protection of private property in any form combined with the exploitation of alien labour. This does not mean that rationality - frequently seen as the central feature of homo informaticus - has to be given up. It still depends on the content and the goals of rational thinking. Today it becomes necessary to look for fresh ways of cooperation, solidarity and mutual help to assure a decent life for everybody and to gain back the control of the economy for the common good.

\section{References}

1. Commons, J. R. Institutional Economics, American Economic Review, Vol.21, pp.648-657, 1931

2. Fleissner, P. Max Webers Bürokratietheorie im Lichte elektronischer Kommunikationsmedien (Max Weber's Theory on Bureaucracy in the Light of the Media of Electronic Communication). In GISI 95 Herausforderungen eines globalen Informationsverbundes für die Informatik F. Huber-Wäschle, H. Schauer und P. Widmayer (Eds.). Springer: Berlin, Germany, 1995; pp. 127-135.

3. Fleissner, P. Von der Stammesgemeinschaft zur Globalgesellschaft - und zurück? (From tribal community to global society - and back?). In Alfred von Liechtenstein (ed.) Internet und Öffentlichkeit. Wiener Vorlesungen Konversatorien und Studien 13. Wien: WUV Universitätsverlag, 2002, pp. 83-96.

4. Marx, K. Capital, Volume I, Chapter 15, 1867. https://www.marxists.org/archive/marx/works/1867$\mathrm{c} 1 / \mathrm{ch} 15 . \mathrm{htm} \# \mathrm{~S} 1$

5. Marx, K. Grundrisse der Kritik der politischen Ökonomie, 1857/1858. https://www.marxists.org/archive/marx/works/1857/grundrisse/ch14.htm

6. Polanyi, K. The Great Transformation the political and economic origins of our time. Beacon Press: Beacon Hill, Boston, 1957.

7. Tönnies, F. Gemeinschaft und Gesellschaft. Grundbegriffe der reinen Soziologie. Dritte durchges. Aufl. Berlin 1920.

8. Weber, M. Soziologische Grundbegriffe. Tübingen: UTB-Taschenbücher 541. Reprint of 1921, 1984; pp. 69-72. 
